\title{
EFFECTIVENESS OF STRUCTURAL TEACHING PROGRAMME ON KNOWLEDGE REGARDING PREVENTION OF NOSOCOMIAL INFECTION AMONG STAFF NURSES IN SELECTED PAEDIATRIC HOSPITALS OF BENGALURU, KARNATAKA, INDIA
}

\author{
Jayalakshmi Narasimhaiah', Praveena Moorthy² \\ 1Professor, Department of Paediatric Nursing, Government College of Nursing, Fort, Bengaluru, Karnataka, India. \\ 2M.Sc Nursing Student, Government College of Nursing, Fort, Bengaluru, Karnataka, India.
}

\begin{abstract}
BACKGROUND
Nosocomial infection or hospital-acquired infections are those acquired during patient's hospitalisation and not present or incubating at the time of admission. All infections diagnosed 48 hours after admission till 72 hours after discharge should be considered as nosocomial infection. Children's immature immune system makes them prone to any type of infection when they visit the health care for their illness. They get infected with hospital infections, may occur due to improper standardised measures to prevent infection. So, nurses should have knowledge regarding the preventive measures to prevent infection.
\end{abstract}

ABSTRACT

\section{MATERIALS AND METHODS}

A quantitative research approach and one group of pre-test and post-test without a control group using pre-experimental design was used for the study. Purposive sampling technique was used to select the sample. Information was collected from 50 registered staff nurses using structured knowledge questionnaire. Structured Teaching Programme (STP) was implemented and post-test was conducted after 7 days of using same questionnaire.

\section{RESULTS}

The overall pre-test knowledge scores of staff nurses on prevention of nosocomial infection among children was found to be $42.5 \%$ and the overall post-test knowledge scores was found to be $85.1 \%$ and enhancement in the mean percentage knowledge score of $42.6 \%$ was found to be significant at $5 \%$ levels for all the aspects under study. There was significant association between post-test knowledge scores and selected demographic variables with professional experience $\left(\chi^{2}=8.42\right)$, experience in paediatric hospital $\left(\chi^{2}=9.98\right)$, in-service education $\left(\chi^{2}=7.23\right)$, source of information $\left(\chi^{2}=15.64\right)$, type of family $\left(\chi^{2}=7.75\right)$, family income $\left(\chi^{2}=8.69\right)$, religion $\left(\chi^{2}=7.15\right)$, ability to recognise nosocomial infection $\left(\chi^{2}=16.54\right)$, intimate the presence of nosocomial infection $\left(\chi^{2}=9.41\right)$ and surveillance of the ward $\left(\chi^{2}=5.99\right)$.

\section{CONCLUSION}

Overall findings showed that there is knowledge deficit among staff nurses regarding prevention of nosocomial infections in paediatric hospitals and structured teaching programme was effective in improving their knowledge.

\section{KEY WORDS}

Structured Teaching Programme, Knowledge, Prevention, Nosocomial Infection, Children, Staff Nurses.

HOW TO CITE THIS ARTICLE: Narasimhaiah J, Moorthy P. Effectiveness of structural teaching programme on knowledge regarding prevention of nosocomial infection among staff nurses in selected paediatric hospitals of Bengaluru, Karnataka, India. J. Evolution Med. Dent. Sci. 2018;7(35):3811-3815, DOI: 10.14260/jemds/2018/855

\section{BACKGROUND}

Nosocomial infection is also termed as hospital-acquired infections. These are infections which develop within the hospital or are produced by microorganisms acquired during hospitalisation. These may afflict not only the patients but also staff members, volunteers, visitors and attendants. Having contact with the hospital, some of the affected individuals may manifest symptoms after discharge from the hospital, e.g. Hepatitis B and some other infection of the newborn. ${ }^{1}$ Measures employed to increase the survival rate in small babies have added greatly to risks of nosocomial infections, for example: IV drip, assisted respiration, parental

'Financial or Other Competing Interest': None.

Submission 14-07-2018, Peer Review 08-08-2018,

Acceptance 14-08-2018, Published 25-08-2018.

Corresponding Author:

Dr. Jayalakshmi Narasimhaiah,

Professor, Department of Paediatric Nursing,

Government College of Nursing, Fort,

Bengaluru-560002, Karnataka, India.

E-mail: jlakshmiraju2000@gmail.com

DOI: $10.14260 /$ jemds $/ 2018 / 855$

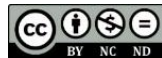

nutrition, lavish use of broad-spectrum antibiotics and extensive surgical manoeuvres on babies with congenital malformations. Sepsis rate in Neonatal Intensive Care Unit (NICU) is among the highest anywhere in the hospital. ${ }^{2}$ According to one report of infection with Mycobacterium tuberculosis, babies born in obstetric unit had converted to tuberculin positive at an extraordinary high rate. This could only be explained by acquisition of hospital infection.

\section{Common Nosocomial Infections are-}

1. Lower Respiratory Tract Infections: which includes Pneumonia, pulmonary tuberculosis, pulmonary aspergillosis, Chlamydia, pneumocystis carinii.

2. Gastroenteritis: organisms responsible are shigella, salmonella, rotavirus, Yesinia, Vibrio cholerae, campylobacter and clostridium difficile.

3. Intravenous Cannula: associated infectious organisms responsible are Klebsiella, staphylococcus aureus, citrobacter and albicans.

4. Surgical Wound Infection: following diagnostic and therapeutic procedures, e.g. Urinary tract catheterisation 
or instrumentation, tracheotomy, continuous IV therapy and surgery.

These infections are a significant problem in neonatal intensive care unit because of frequent intervention and use of that bypass skin and mucosal barriers, urinary catheters and mechanical ventilation. The nosocomial infections increase the duration of study in hospital and also the cost of therapy, overall mortality attribute to nosocomial infection is about $40 \% .^{3}$

The European prevalence of infection in Intensive Care Study (EPIC) involving over 4500 patients demonstrated that the nosocomial infection prevalence rate in ICU was $20.6 \%$. In ICU patients are particularly at risk of nosocomial infections as a result of mechanical ventilation, use of invasive procedures and their immune compromised status. ${ }^{4}$ Respiratory Syncytial Viral (RSV) frequently causes nosocomial outbreaks in general paediatric wards and occasionally in neonatal intensive care units. The primary blood stream infections are the commonest nosocomial infections $(20-30 \%)$ in Neonatal Intensive Care Units followed by the lower respiratory tract infections (20 - 25\%) staphylococcus, Klebsiella, E. coli, pseudomonas aeruginosa, enterococci and Candida are the commonly implicated pathogens. 5

The nosocomial infection is a problem worldwide over in all the hospitals. However, due to emergence of HIV infection the need to prevent and control nosocomial infection is being emphasised. The aim is to reduce nosocomial infection and ensure that no one acquires HIV infection from the hospital by strictly observing the precautions recommended for handling blood and body fluids, precautions in relation to injections, skin piercing and invasive procedures, effective use of sterilisation, disinfection and disposal of infective waste. 6

In a recent survey conducted by WHO on 28,861 patients in 47 hospitals of 14 countries located in 4 continents, the prevalence rate of nosocomial infection of different hospitals varied from $3 \%-21 \%$ with mean of $8.4 \% .^{7}$ Infections occur within 48 hours after admission are considered as nosocomial infection. Nosocomial infection cannot be eradicated entirely, but many of them can be prevented by proper aseptic measures. ${ }^{5}$

\section{Need for the Study}

The hospital-based programs of surveillance, prevention and control of healthcare-associated infections have been in place since the 1950s. The study on the Efficacy of Nosocomial Infection Control Project (SENIC) from the 1970s showed that nosocomial infection rates could be reduced by $32 \%$ if infection surveillance were coupled with appropriate infection control programs. In 2005, the National Healthcare Safety Network (NHSN) was established with the purpose of integrating and succeeding previous surveillance systems at the Centres for Disease Control and Prevention (CDC), National Nosocomial Infections Surveillance (NNIS), Dialysis Surveillance Network (DSN) and National Surveillance System for Healthcare Workers (NaSH). ${ }^{8}$

In the burns unit, 36.2 percent infection was found per 1000 patients per day in the renal transplant unit. Hospital acquired infections were reported in 58 patients out of 100 . The extent of ventilator associated pneumonia was found to be 30.7 percent per 1000 ventilator days in the gynaecology department, 15 percent of urinary tract infections were attributed to HAIs and 9 percent of wound infection rate was attributed to HAIs. ${ }^{9}$

About $5-10 \%$ in most developed nations in India, one in four patients admitted to hospital acquires HAI. In US around 1.7 million HAI's occur each year and 99,000 people lose their lives. In Europe, around 25,000 deaths occur each year. Overall, there are about 2 million annual cases of HAI's in developed nations. Frequency of HAI's in developed nations is 5 - 10. In India Nosocomial infection rate is at over $25 \%$, Frequency is 1 in every 4 patients admitted into the hospital and $1 / 3$ rd of all such infections are preventable. ${ }^{10}$ In the United States, priorities for nosocomial infection prevention and control efforts include infections caused by emerging pathogens such as coagulase-negative staphylococci, enterococci and Candida species, infections of the blood stream, surgical wounds and infections in critical care units. ${ }^{11}$ Hand washing is probably the most important infection control procedure. The choice of barrier controls should be decided by individual institutions depending on the patients, the type of ward and the benefit relative to cost. ${ }^{12}$

The Global Patient Health Challenge Program was initiated in India last month. It has been proven that HAIs lead to complications among 3.5 to 16.6 percent admitted patients worldwide. Most common types of HAIs are surgical wounds, urinary tract infections and lower respiratory tract infections. These can be found among patients admitted to ICUs, labour rooms and among patients undergoing invasive procedures or those on immunosuppressive drugs. ${ }^{13}$

The guidelines are intended to provide evidence-based recommendations for preventing catheter-related infections. Major areas of emphasis include- 1) Educating and training healthcare providers who insert and maintain catheters; 2) Using maximal sterile barrier precautions during central venous catheter insertion; 3) Using a $2 \%$ chlorhexidine preparation for skin antisepsis; 4) Avoiding routine replacement of central venous catheters as a strategy to prevent infection; and 5) Using antiseptic/ antibiotic impregnated short-term central venous catheters. These guidelines also identify performance indicators that can be used locally by health care institutions or organisations to monitor their success in implementing these evidence-based recommendations. 14

\section{Aims and Objectives}

The present study was to evaluate the effectiveness of structured teaching programme on knowledge regarding prevention of nosocomial infection in children among staff nurses in selected paediatric hospitals.

\section{Conceptual Framework}

The conceptual framework for this study was developed by the investigator adopted from health promotion modelPender (1996). It was designed to be a complementary counterpart to models of health protection. Health promotion is directed at increasing client levels of well-being. Pender's health promotion model seeks to increase individual health promotion activities. The model focuses on cognitive, perceptional and modifying factors and participation in health promotion behaviour. The model also identifies factors that influence the health promotion activities. 


\section{MATERIALS AND METHODS}

A quantitative research approach and one group pre-test and post-test without a control group using pre-experimental design was used for the study. Purposive sampling technique was used to select the sample. 50 staff nurses working in NICU, PICU, medical wards, surgical wards and OPD were selected for the study. In the present study, the following tools were used-

Part-I: Consists of 14 items related to socio-demographic data.

Part-II: Structured knowledge questionnaire consisted of 50 items on knowledge of the staff nurses regarding the prevention of nosocomial infection among children. Each item of the questionnaire has one correct answer, every correct answer would fetch one mark and the total score of the knowledge questionnaire is 50. Each correct answer was given a score of 'one' mark and wrong answers 'zero' score. The tool developed and used for the data collection was structured knowledge questionnaire. 11 experts validated the content validity of the tool and the tool was found to be reliable and feasible. The reliability of the tool was established by Karl Pearson coefficient of correlation where $r=0.99$. The teaching plan consisted of various aspects on prevention of nosocomial infection. The teaching plan was organized in sequence and in continuity. After obtaining permission from the Medical Superintendent of paediatric hospitals, the investigator explained the need and assured them of the confidentiality of their responses. The pre-test was administered followed by a teaching program. Post-test was administered 7 days after teaching plan by using same questionnaire used in pre-test. The Data gathered were analysed, and interpreted according to objectives.

\section{Inclusion Criteria}

- Staff nurses who were willing to participate in the study.

- Staff nurses who consented to participate in the study.

- Staff nurses who were available at the time of data collection.

\section{Exclusion Criteria}

- Staff nurses not willing to participate in the study.

- Study will not include nurses not working in paediatric hospitals.

\section{Statistical Analysis}

The data obtained was analysed in terms of the objectives of the study using descriptive and inferential statistics. Frequency, percentage, mean and standard deviation were used to classify the baseline data. Chi-square test was used to find the association between socio-demographic variables with knowledge scores. Paired ' $t$ ' test was used to ascertain whether there is significant difference in the mean knowledge score of pre-test and post-test values. The data was analysed using the Statistical Package for Social Sciences (SPSS version 19).

\section{RESULTS}

The findings of this study would assist in identification of the staff nurses' knowledge regarding prevention of nosocomial infection. A total of 50 respondents, out of which $50 \%$ (25) of the respondents were from the age group of 30 - 35 years and based on the gender $58 \%$ (29) of the respondents were females. Majority $82 \%$ (41) of the respondents were married and $42 \%$ (21) of the respondents had Diploma in Nursing. $46 \%$ (23) of the respondents had professional experience between 6 and 9 years and 48\% (24) respondents had experiences in paediatric hospital between 1 and 2 years. Majority 70\% (35) of the respondents had not undergone any in-service education training programmes on nosocomial infection. $42 \%$ (21) of them gained knowledge regarding prevention of nosocomial infection from print media as the source of information.

$\mathrm{N}=50$

\begin{tabular}{|c|c|c|c|c|c|c|}
\hline \multirow{3}{*}{$\begin{array}{c}\text { Knowledge } \\
\text { Level }\end{array}$} & \multirow[t]{3}{*}{ Category } & \multicolumn{4}{|c|}{$\begin{array}{c}\text { Classification of } \\
\text { Respondents }\end{array}$} & \multirow{3}{*}{$\begin{array}{c}\chi^{2} \\
\text { Value }\end{array}$} \\
\hline & & \multicolumn{2}{|c|}{ Pre-Test } & \multicolumn{2}{|c|}{ Post-Test } & \\
\hline & & No. & $\%$ & No. & $\%$ & \\
\hline Inadequate & $\begin{array}{l}\leq 50 \% \\
\text { Score }\end{array}$ & 29 & 58.0 & 0 & 0.0 & \multirow{4}{*}{$59.02 *$} \\
\hline Moderate & $\begin{array}{c}51-75 \% \\
\text { Score }\end{array}$ & 21 & 42.0 & 20 & 40.0 & \\
\hline Adequate & $\begin{array}{l}>75 \% \\
\text { Score }\end{array}$ & 0 & 0.0 & 30 & 60.0 & \\
\hline Total & & 50 & 100.0 & 50 & 100.0 & \\
\hline
\end{tabular}

*Significant at $5 \%$ level, $\chi^{2}(0.05,2 \mathrm{df}=5.991)$.

The above table reveals that in pre-test $58 \%$ of the nurses possess inadequate knowledge and remaining $42 \%$ of nurses possess moderate knowledge. Whereas in the post-test results, $60 \%$ of them have adequate knowledge and $40 \%$ have moderate knowledge. There has been an improvement in the knowledge level of the staff nurses. The Chi-square value of 59.02 test indicates the enhancement to be significant at $5 \%$ level, which shows the effectiveness of STP on prevention of nosocomial infection $\chi^{2}(0.05,2 \mathrm{df})=5.991$. The above findings are depicted in Fig. 1 .

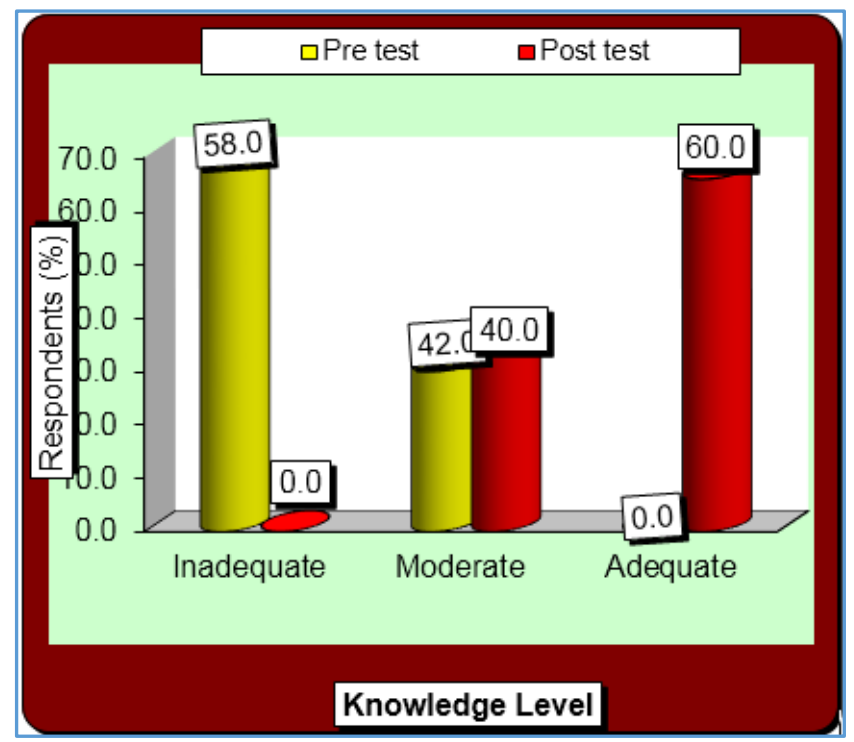

Figure 1. Classification of Staff Nurses on Knowledge Level $\mathrm{N}=50$ 


\begin{tabular}{|c|c|c|c|c|c|c|}
\hline \multirow[b]{2}{*}{ Aspects } & \multirow[b]{2}{*}{$\begin{array}{l}\text { Max. } \\
\text { Score }\end{array}$} & \multicolumn{4}{|c|}{ Respondent's Knowledge } & \multirow{2}{*}{$\begin{array}{c}\text { Paired } \\
\text { 't' } \\
\text { Test }\end{array}$} \\
\hline & & Mean & SD & $\begin{array}{c}\text { Mean } \\
(\%)\end{array}$ & SD (\%) & \\
\hline Pre-test & 50 & 21.24 & 9.1 & 42.5 & 18.1 & \multirow[b]{2}{*}{$20.49 *$} \\
\hline Post-test & 50 & 42.56 & 5.7 & 85.1 & 11.4 & \\
\hline Enhancement & 50 & 21.34 & 7.3 & 42.6 & 14.7 & \\
\hline \multicolumn{7}{|c|}{$\begin{array}{c}\text { Table 2. Overall Pre-test and Post-test Mean Knowledge on } \\
\text { Prevention of Nosocomial Infection }\end{array}$} \\
\hline
\end{tabular}

*Significant at 5\% level, t $(0.05,49 \mathrm{df})=1.96$

The findings in the above table reveal that the post-test mean percentage knowledge score was found higher (mean percentage $=85.1$ and SD percentage $=11.4$ ) when compared with pre-test mean percentage knowledge score value which was 42.5 percentage with SD of 18.1 percentage (mean knowledge enhancement score was $42.6 \%$ ). The statistical paired ' $\mathrm{t}$ ' test implies that the difference in the pre-test and post-test value was found statistically significant at $5 \%$ level ( $p<0.05$ ) with a paired ' $t$ ' test value of 20.49. There exists a statistical significance in the enhancement of knowledge score indicating the positive impact of intervention programme. The above findings are depicted in Fig. 2.

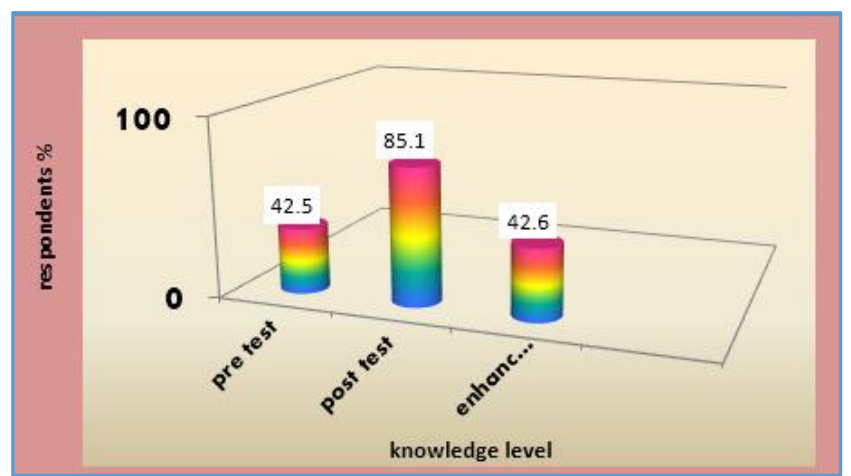

Figure 2. Overall Pre-test and Post-test Mean Knowledge of Staff Nurses on Prevention of Nosocomial Infection

There was significant association between post-test knowledge scores and selected demographic variables with professional experience $\left(\chi^{2}=8.42\right)$, Experience in paediatric hospital $\left(\chi^{2}=9.98\right)$, in-service education $\left(\chi^{2}=7.23\right)$, source of information $\left(\chi^{2}=15.64\right)$, type of family $\left(\chi^{2}=7.75\right)$, family income $\left(\chi^{2}=8.69\right)$, religion $\left(\chi^{2}=7.15\right)$, recognise nosocomial infection $\left(\chi^{2}=16.54\right)$, intimate the presence of nosocomial infection $\left(\chi^{2}=9.41\right)$, surveillance of the ward $\left(\chi^{2}=5.99\right)$. However, there was no significant association between age $\left(\chi^{2}=0.03\right)$, sex $\left(\chi^{2}=0.06\right)$, marital status $\left(\chi^{2}=3.25\right)$ and professional qualification $\left(\chi^{2}=0.71\right)$, total clinical experience and knowledge level of respondents on prevention of nosocomial infection $\left(\chi^{2}=1.59\right)$.

\section{DISCUSSION}

Out of 50 nurses, 30\% had undergone in-service education training program and $70 \%$ did not attend training program on prevention of nosocomial infection. A related study was conducted on regular in-service education program. Infection control measures coupled with continuous surveillance of hospital-acquired infection would result in attaining highest standard of infection control practices. Data revealed the mean knowledge and mean practice of staff nurses regarding infection control measures to be $73.1 \%$ and $62.7 \%$ respectively. 15

With respect to source of information on prevention of nosocomial infection, all the respondents were trained during their course. $42 \%$ of nurses received information from print media, 30\% from health professionals, $14 \%$ from friends and relatives and $8 \%$ from electronic media. A related study was conducted, and the results were overall mean percentage score of the participants on ICSQ was $65.4 \pm 2.58$ with medical, physiotherapy, radiography and nursing students recording mean percentage scores of $70.58 \pm 0.62,65.02 \pm$ $2.00,64.74 \pm 1.19$ and $61.31 \pm 2.35$, respectively. The main source of information about the prevention of nosocomial infections as cited by participants was their routine formal training in class. 16

The present study confirmed that there was a considerable improvement of knowledge after the structured teaching programme and is statistically established as significant. The overall mean percentage knowledge score in the pre-test was $42.5 \%$ and $85.1 \%$ in the post-test. This shows the enhancement of knowledge by $42.6 \%$ after the structured teaching programme. These findings were similar to another study that was conducted, and the results revealed that staff nurses (56.66\%) have adequate knowledge regarding infection control measures. Staff nurses working in nursery have higher knowledge score (45.7\%) than labour room and postnatal ward (39\%). Most of the staff nurses have unsatisfactory practices $(61.66 \%)$ regarding infection control measures. This is due to inadequate manpower and resources. ${ }^{17}$ This educational programme leads to gain in knowledge, which may have an impact on prevention of nosocomial infection.

\section{Recommendations}

On the basis of the findings of the study following recommendations have been made-

- A similar study can be done on a large sample to generalize the findings.

- Plan for mandatory in-service education and post diploma courses on prevention of hospital acquired infection.

- Administrator should provide sufficient manpower and material for the hospitals to the care of patients from nosocomial infections.

- An experimental study can be undertaken with a control group for effective comparison of the result.

- A study can be conducted by including additional demographic variables.

- A comparative study can be conducted between nurses working in government and private hospital settings.

- Manuals, information booklets and self-instruction module may be developed in areas of risk factors, causes and symptoms of nosocomial infection and documentation.

- A study can be carried out to evaluate the efficiency of various teaching strategies like Self-Instructional Module, pamphlets, leaflets and computer-assisted instruction on hospital-acquired infection. 


\section{CONCLUSION}

Nosocomial Infection is a worldwide problem. To prevent nosocomial infection, staff nurses working in paediatric wards have to be educated, as they are the backbone of health care services. This can be done by providing frequent inservice education to update their knowledge. The study showed that there was knowledge deficit among staff nurses regarding prevention of nosocomial infection, and structured teaching programme was effective in improving their knowledge to prevent nosocomial infection.

\section{REFERENCES}

[1] Vincent JL V, Bihari DJ, Suter PM, et al. The prevalence of nosocomial Infections in intensive care units in Europe. Results of the European Prevalence of infection in Intensive Care (EPIC) study. EPIC International Advisory Committee JAMA 1995;274(8):639-44.

[2] Suraj G. The short textbook of paediatrics. 10 $0^{\text {th }}$ edn. New Delhi: Jaypee Brothers Medical Publishers (P) Ltd., 2004: p. 218-20.

[3] Marlow DR. Text book of paediatric nursing. $6^{\text {th }}$ edn. Philadelphia: Harcourt Publication 1988: p. 422-3.

[4] Van den Bruel A, Haj-Hassan T, Thompson M, et al. Diagnostic value of clinical features at presentation to identify serious infection in children in developed countries: a systematic review. Lancet 2010;375(9717):834-45.

[5] Hockenberry MJ. Wong's essentials of paediatric nursing. $7^{\text {th }}$ edn. Elsevier 2005: p. 734-5.

[6] Aditi Tandon. Tribune news service, PGI, plans to control hospital acquired infections. Journal list $>$ crit care> 2007;11(1):101. doi-10.11 86/cc5116.

[7] Mirza A, Steel RW. Hospital acquired infections meds care drugs and diseases and procedures. Apr 27, 2011. http:// Emedicine, medscapfa. Com/article/9670

[8] Nosocomial Infection National Surveillance Service (NINSS). Surveillance of Hospital acquired Bacteraemia in English Hospitals, 1997-2002. London.
[9] Hospital Infection Working Group of the Department of Health and Public Health Laboratory Service: Hospital Infection Control. Guidance on the control of infection in hospitals. London: Department of Health, 1995.

[10] Haley RW, Culver DH, White JW, et al. The efficacy of infection surveillance and central programs in preventing nosocomial infections in US hospitals (SENIC). Am J Epidemiol 1985;121(2):182-205.

[11] Kasper DL, Braunwald E, Fauci A, et al. Harrison's Principles of internal medicine. $16^{\text {th }}$ edn. New York: McGraw-Hill Professional Medical Publishers 2005. p. 104.

[12] Vaideeswar P, Bavdekar SB, Jadhav SM, et al. Necrotizing adenoviral pneumonia: manifestation of nosocomial infection in pediatric intensive care unit. Indian J Pediatr 2008;75(11):1171-4.

[13] Hall CB. Nosocomial respiratory syncytial virus infections: the "Cold War" has not ended. Clin Infect Dis 2000;31(2):590-6.

[14] Mayon-White RT, Ducel G, Kereselidze T, et al. An international survey of the prevalence of hospitalacquired infection. J Hosp Infect 1988;11(Suppl A):438. http://www/faqs.org/abstracts/Health/Hospitalacquired-infections-in-children

[15] Vij A, Williamson SN, Gupta S. Knowledge and practice of nursing staff towards infection control measures in a tertiary care hospital. Journal of the Academy of Hospital Administration (2001-07 - 2001-12):13(2).

[16] Bello AI, Asiedu EN, Adegoke BO, et al. Nosocomial infections: knowledge and source of information among clinical health care students in Ghana. Int J Gen Med 2011;4:571-4.

[17] Bala J. Abstracts knowledge and practices of staff nurses regarding infection control in $\mathrm{MCH}$ area of a selected Hospital Ludhiana, Punjab: $6^{\text {th }}$ International Neonatal Nursing Conference - ICNN,ICNN/CIPR/21, 2007: p. 69. 